\title{
A POTENCIALIDADE DOS ENCONTROS COM A REDE DE PROTEÇÃO SOCIAL NA JUSTIÇA JUVENIL RESTAURATIVA
}

Glaucia Mayara Niedermeyer Orthi $₫ 0000-0002-8829-4722$

Universidade Cesumar - UNICESUMAR

Dircéia Moreira ${ }^{\text {ii }}$ 0000-0001-6203-0246

Universidade Estadual de Ponta Grossa - UEPG

Jussara Ayres Bourguignon ${ }^{\text {iii }} \oplus 0000-0002-2448-4121$

Universidade Estadual de Ponta Grossa - UEPG

RESUMO: O artigo objetivou investigar a potencialidade dos encontros de profissionais da rede de proteção social com os adolescentes autores de ato infracional e seus familiares na justiça restaurativa para o enfrentamento das condições de vulnerabilidade social e acesso a direitos. Realizamos pesquisa bibliográfica e entrevistas semiestruturadas com adolescentes, familiares, facilitadores e membros da rede de proteção social de quatro cidades do país: Caxias do Sul-RS, Ponta Grossa-PR, Belém-PA e Santarém-PA. Os depoimentos dos participantes foram analisados com base na literatura sobre emoções, segundo Espinosa, Vigotski, Marilena Chauí e Bader Sawaia. Concluímos que a autonomia, o protagonismo das famílias, a ampliação da capacidade de escolha e de controle sobre sua vida é um produto que emerge das relações que se estabelecem entre profissionais e famílias, quando regidos por uma lógica intersetorial, pela horizontalidade das relações entre familiares e profissionais, pelo vínculo e afeto mobilizados nos encontros.

PALAVRAS-CHAVE: Ato infracional. Vulnerabilidade social. Intersetorialidade.

\section{THE POTENTIALITY OF MEETINGS WITH THE SOCIAL PROTECTION NETWORK IN RESTAURANT JUVENILE JUSTICE}

\begin{abstract}
The article aimed to investigate the potential of the meetings of professionals from the social protection network with adolescent authors of an infraction and their families in restorative justice to face the conditions of social vulnerability and access to rights. We conducted bibliographic research and semi-structured interviews with teenagers, family members, facilitators and members of the social protection network of four cities in the country: Caxias do Sul-RS, Ponta Grossa-PR, Belém-PA and Santarém-PA. The participants' testimonies were
\end{abstract}

analyzed based on the literature on emotions, according to Espinosa, Vigotski, Marilena Chauí and Bader Sawaia. We conclude that autonomy, the protagonism of families, the expansion of the ability to choose and control their lives is a product that emerges from the relationships that are established between professionals and families, when governed by an intersectoral logic, by the horizontality of relationships between family members and professionals, for the bond and affection mobilized in the meetings.

KEYWORDS: Offense social. Vulnerability. Intersectoriality. 


\section{Introdução}

Este Relato de Pesquisa é parte de nossa tese de doutorado, que objetivou investigar a justiça juvenil restaurativa e a articulação com a rede de proteção social no atendimento ao adolescente em contexto de vulnerabilidade social no Brasil. A justiça restaurativa na socioeducação foi prevista na Lei $\mathrm{n}^{\circ}$ 12.594/2012 que instituiu o Sistema Nacional de Atendimento Socioeducativo (SINASE) e deu prioridade às práticas restaurativas, a fim de responsabilizar o adolescente e atender às necessidades das vítimas (BRASIL, 2012, art. 35, inciso III). Recortamos de nossa tese a categoria de análise sobre a potencialidade dos encontros de profissionais da rede de proteção social com os adolescentes autores de ato infracional e seus familiares na justiça restaurativa. Isso porque compreendemos o ato infracional como a expressão de vulnerabilidades sociais.

Para Silva e Oliveira (2015), a "[...] vulnerabilidade social constituiria uma categoria de mediação entre a desigualdade/exclusão social e a violência entre jovens [...]” (p. 14), por alimentar frustrações quanto às impossibilidades de consumir e de se identificar com o socialmente valorizado. "A desigualdade social exprime uma circunstância relativa de privação de direitos que amplifica a vulnerabilidade social da população pobre" (SILVA; OLIVEIRA, 2015, p. 14). Com isso, os autores ressaltam que a dificuldade no acesso de jovens às políticas sociais de proteção, notadamente educação e trabalho, enquanto instrumentos para a mobilidade e inclusão social, contribui para a ampliação da situação de vulnerabilidade social, o que torna os jovens mais desprotegidos e mais expostos, por sua vez, à inclusão no crime organizado e às mortes violentas, por exemplo (SILVA; OLIVEIRA, 2016). É neste contexto em que a justiça juvenil restaurativa se insere no país e é a partir dele que as intervenções e estudos acerca da justiça restaurativa precisam ter como parâmetro, assumindo o compromisso de fazer o enfrentamento às vulnerabilidades sociais que rondam o ato infracional.

\section{Metodologia}

Propusemos uma pesquisa orientada pelo método do materialismo histórico e dialético, que nos leva a apreender a essência do fenômeno que pretendemos pesquisar. Esse movimento parte da realidade aparente do fenômeno em direção à sua essência, “[...] capturando a sua estrutura e dinâmica, por meio de procedimentos analíticos e operando a sua síntese [...]", reproduzindo-a, assim, no "[...] plano do pensamento; mediante a pesquisa, viabilizada pelo 
método, o pesquisador reproduz, no plano ideal, a essência do objeto que investigou" (NETTO, 2009, p. 05).

Com o objetivo de colaborar para o entendimento acerca da potencialidade dos encontros com a rede no atendimento ao adolescente autor de ato infracional e sua família e, também, subsidiar as intervenções da justiça juvenil restaurativa na articulação com a rede de proteção social, desenvolvemos neste artigo uma pesquisa bibliográfica em torno das “emoções”, a partir de Espinosa, Marilena Chauí, Vigotski e Bader Sawaia, de forma articulada com os depoimentos dos participantes da pesquisa empreendida no doutorado. Com isso, objetivamos compreender sobre os “bons encontros", segundo Espinosa, proporcionados pela metodologia do círculo de construção de paz, amplamente empregada no Brasil enquanto metodologia da justiça restaurativa, entre adolescentes, familiares e profissionais da rede de proteção social no enfrentamento às condições de vulnerabilidade e acesso a direitos.

A pesquisa contou com entrevistas realizadas com participantes de 4 cidades: Caxias do Sul-RS, Ponta Grossa-PR, Belém-PA (incluindo o distrito de Icoaraci) e Santarém-PA. Os participantes da pesquisa foram: 1) coordenadores/informantes/facilitadores de círculos de construção de paz no atendimento à justiça juvenil restaurativa; 2) adolescentes e familiares; e 3) membros da rede de proteção social. Ao todo foram realizadas 39 entrevistas semiestruturadas, porém neste artigo contamos com o depoimento de 10 participantes. Os nomes dos participantes da pesquisa foram aleatoriamente substituídos, a fim de preservar o anonimato dos entrevistados. Além disso, a pesquisa foi submetida e aprovada pelo Comitê de Ética em Pesquisa, sob protocolo CAAE: 85406918.7.0000.0105.

\section{Resultados e discussão}

A participação na justiça juvenil restaurativa, em particular nos círculos de construção de paz, metodologia que foi dominante na pesquisa realizada, foi entendida pelos participantes como uma vivência, também, afetiva. O conflito, o ato infracional, a ofensa praticada e sentida são vivências permeadas de paixões tristes, no entendimento de Espinosa, que diminuem nossa capacidade de agir. Nestas circunstâncias é possível observar prejuízos à própria saúde mental dos envolvidos, além dos demais danos e consequências trazidos pela ofensa, tanto a vítimas e ofensores, quanto comunidade. Ao trazer a dimensão das emoções como, também, determinantes das ações humanas, tanto aquelas que promovem a liberdade quanto as que promovem a servidão, reconhecemos que as mudanças que podem ser realizadas pelos homens 
por meio de uma ação autônoma e consciente, necessariamente, atravessam a dimensão afetiva.

O sentir é constantemente enfatizado nos círculos restaurativos, que não procuram reiterar qual foi a lei violada, e sim o que isto significou para a vítima e para todos os envolvidos (PRANIS, 2010). A própria estrutura do círculo é desenhada para que se enxergue o outro como um ser humanizado e não como coisa/objeto, e este reconhecimento só se dá na esfera das emoções, em circunstâncias de participação igualitária, com responsabilidade compartilhada, em que as necessidades de todos sejam atendidas. Pranis (2010) esclarece que os círculos são operacionalizados por meio de contação de histórias, pois são elas que mobilizam uma escuta atenta e diferenciada de argumentações e informações apresentadas de forma cognitiva. Ao ouvirmos uma história, o "corpo relaxa, se acalma, fica mais aberto e menos ansioso. Absorvemos a história antes de avaliar seu conteúdo. Somos envolvidos emocionalmente, além de mentalmente [...], o que leva a uma compreensão muito maior entre as pessoas" (PRANIS, 2010, p. 56).

A mesma mensagem quando transmitida por uma história vivida envolve muito mais os participantes do que um conselho ou uma "reconciliação forçada":

Elisa: Eu acho que é importantíssimo porque cada um né, a partir do roteiro que vocês seguem, cada um faz uma contribuição que faz a criança, o pessoal que tá ali, $[. .$.$] de perceber que existem várias realidades e que as$ coisas podem dar errado, podem dar certo, então utiliza-se como... como exemplo mesmo, aquilo toca um pouco mais fundo do que de repente só uma conversa entre os dois né. (Diretora de escola, Ponta Grossa)

Clara: [...] e com isso você consegue trabalhar muito o relacionamento, os sentimentos que não estão bem resolvidos, então é uma maneira de, indiretamente, sem dizer a você "vai lá falar da tua vida", você não fala isso para criança, você vai jogando pergunta, você vai fazendo as dinâmicas e ali a coisa vai fluindo naturalmente. Em uma pergunta sai coisa que você, "poxa, não imaginava que ele passou por isso" ou que isso ainda tá guardado com ele. Então eu achei que esse resgate assim é bem importante. (Assistente Social, Ponta Grossa)

É por essa razão, em especial, que os círculos e a justiça restaurativa diferem do modo tradicional de resolução de conflitos, pois antes de abordar o problema e as consequências danosas, os participantes são convidados a contar e a ouvir histórias, que se permitam emocionar-se e tenham a possibilidade de compreender o que aconteceu a partir desse caminho afetivo:

Abrindo nossa história individual aos outros, permitimos que eles se liguem a nós, encontrando pontos em comum conosco e nos conhecendo melhor. Num 
relacionamento respeitoso entre orador e ouvinte, os dois se abrem a uma ligação mais profunda com o outro. Quando as pessoas partilham histórias de dor e erros, e deixam cair camadas protetoras revelando-se como seres humanos vulneráveis e batalhadores, nós nos identificamos mais com essas pessoas. Fica muito mais difícil manter distância daquele outro e deixar de sentir a ligação existente em função da humanidade comum que nos une. Fica mais difícil apegar-se ao medo, à raiva ou à indiferença que sentimos em relação a alguém quando este expõe sua dor e vulnerabilidade. A menos que já conheçamos a história de vida daquele que está falando, a escuta das histórias de sofrimento e fragilidade em geral desmancha os preconceitos que tínhamos a seu respeito (PRANIS, 2010, p. 56-7, grifo do autor).

Podemos ilustrar os ensinamentos de Pranis (2010), pelo seguinte depoimento de uma participante da pesquisa:

Isadora: [...] Eu também tenho uma experiência de adolescentes que são resistentes ao diálogo, por não acreditam mesmo no adulto, por se perceberem sempre julgados, então eles silenciam, e houve uma experiência de um adolescente, eram 3 adolescentes, o círculo foi bem legal, e tinha um adolescente, eles eram rivais, de alas diferentes, e eu não sabia que tinha uma certa rivalidade, mas tinha a mãe de um, tinha a irmã do outro, tinha a família, foi um círculo bem legal, e o adolescente manifestando toda a sua resistência ele ficava de lado na cadeira, pegava o bastão, passava, não falava nada, mostrando total resistência. Aí houve uma questão é... que a mãe do outro começou a chorar e disse que ela tinha perdido um filho assassinado e ela foi relatando a dor de ter perdido um filho assassinado, de ter outro filho de 13, tal, tal, tal e foi assim nesse momento, que nessa dor esse adolescente estabeleceu uma conexão, quando o bastão chegou na mão dele ele virou, aí ele disse para ela "eu não sabia que tinha acontecido isso com a senhora" e disse "olha, eu sei a sua dor, o meu padrasto assassinou a minha mãe na minha frente", aí ele começou a falar, gente! Foi um momento único... nem a técnica de referência sabia desse episódio na vida dele que aconteceu muito antes dele cometer o ato infracional [...]. (Facilitadora, Santarém)

Considerando esse importante aspecto presente nos círculos de justiça restaurativa iremos abordar o entendimento de Espinosa sobre os afetos e a apropriação que um importante psicólogo russo, chamado Lev Semenovitch Vigotski, fez da sua teoria, para que seja possível orientar a análise destes resultados de pesquisa.

Espinosa representou verdadeira subversão à filosofia de seu tempo e dos tempos seguintes com o seu pensamento, liberando a filosofia do peso de duas tradições: "a da transcendência teológico-religiosa ameaçadora, fundada na ideia de culpa originária e na imagem de um Deus juiz; e a da normatividade moral, fundada na heteronímia do agente [...]" (CHAUÍ, 2011, p. 68). Apesar de romper com importantes concepções da filosofia clássica, tais como a ideia de Deus, a relação entre alma e corpo, paixão e razão, liberdade e necessidade (natureza), a tradição clássica ainda perdurou como forte concepção pelos séculos seguintes. 
A tradição clássica na filosofia entendia a paixão como impulsos e apetites que levavam a um domínio da alma pelo corpo, devendo a razão a ela se opor, para nos liberar da paixão (CHAUÍ, 2011). Este entendimento sobre a paixão afastou a emoção enquanto componente constitutivo do ser humano, atribuindo a ela caráter de menor qualidade e importância na vida e na ciência.

Sobre o corpo, Espinosa revoluciona ao afirmar que o corpo “[...] não é uma unidade isolada que entraria em relação com outras unidades isoladas, mas é um ser originária e essencialmente relacional [...]", constituído por relações internas e externas com outros, afetando e sendo afetado por outros corpos (CHAUÍ, 2011, p. 73).

O corpo, sistema dinâmico complexo de movimentos internos e externos, pressupõe e afirma a intercorporeidade como originária sob dois aspectos: de um lado, porque ele é, enquanto um ser singular, uma união de corpos; de outro, porque sua vida se realiza na coexistência com outros corpos externos. Não só o corpo está exposto à ação de todos os outros corpos exteriores que o rodeiam e dos quais precisa para conservar-se, regenerar-se e transformar-se, como ele próprio é necessário à conservação, regeneração e transformação de outros corpos. Um corpo humano é tanto mais forte, mais potente, mais apto à conservação, à regeneração e à transformação, quanto mais ricas e complexas forem suas relações com outros corpos, isto é, quanto mais amplo e complexo for o sistema das afecções corporais (CHAUÍ, 2011, p. 73, grifo do autor).

“Corpo é matéria biológica, emocional e social” (SAWAIA, 2011, p. 103). Para Espinosa, corpo e alma/mente são da mesma substância, ambos apresentam uma relação de simultaneidade e interdependência, não há hierarquia na relação entre corpo e mente. "O homem [...] é a unidade de duas ordens de realidade internamente articuladas ou de duas potências de agir; é um ser cuja unidade se exprime diferenciadamente pelas operações corporais e psíquicas" (CHAUÍ, 2011, p. 76). A mente é consciência do corpo, ligada ao seu objeto de pensamento - o corpo:

De que mente é ideia? Ela não é ideia de uma máquina corporal observada de fora e sobre a qual formaria representações. Precisa Espinosa: ela é ideia das afecções corporais. Em outras palavras, a mente é consciência dos movimentos, das mudanças, as ações e reações de seu corpo na relação com outros corpos, das mudanças no equilíbrio interno de seu corpo sob a ação das causas externas e internas (CHAUÍ, 2011, p. 79).

Tal relação, entretanto, não significa que a todo tempo a mente tenha ideias verdadeiras sobre seu corpo e sobre si, entrando em cena a imaginação, que traz um conhecimento inadequado sobre o que se passa com seu corpo: "a imagem é o que está separado de sua causa real e verdadeira e, por esse motivo, leva a mente a fabricar causas imaginárias para o que se 
passa em seu corpo, nos demais corpos e nela mesma [...]". Para Espinosa, "os homens são conscientes de seus apetites e desejos, mas ignorantes das causas que os levam a apetecer e desejar" (CHAUÍ, 2011, p. 81). Nessa perspectiva, Espinosa aborda a paixão enquanto passividade, uma vez que a sua origem é entendida como uma causa inadequada, mobilizando afetos que nos afastam dos demais humanos. Sobre a passividade, podemos exemplificar com os seguintes depoimentos, que retratam os participantes antes de participar da justiça juvenil restaurativa:

Rodrigo: Ah, era aquele negócio, como eu falei pra você, que eu era um cara metido a briga, eu chegava aqui eu chegava aqui com os bração, levantava, eu chegava com o biquinho assim nas sobrancelhas tipo, na maioria das vezes eu tomava a palavra dela (assistente social), hoje eu chego eu peço licença, eu bato na porta, eu chego no respeito, antes não, eu chegava pagando de maloqueiro. (Adolescente, Ponta Grossa)

Mateus: Eu era tipo, mais bravo com todos os alunos que vinham com brincadeirinha besta para mim, agora eu mudei, as pessoas que vem brincar comigo eu levo tudo na brincadeira. Parei de ser tipo, que eu era mais briguento, agora não sou mais. (Adolescente, Ponta Grossa)

Espinosa distingue os afetos em passivos (paixões) e ativos (ações): "Por afeto entendo as afecções do corpo pelas quais sua potência de agir é aumentada ou diminuída, estimulada ou refreada, e, ao mesmo tempo, as ideias dessas afecções" (SPINOZA, 2009, parte III, definição 3). Sobre isso, um conceito de grande importância para Espinosa é o que ele denomina de conatus, que é a potência ou a força interior do Homem em perseverar na própria existência (SAWAIA, 2009).

O conatus é a potência interna de autopreservação na existência que toda essência singular ou todo ser singular possui porque é expressão da potência infinita da substância. Os humanos, como os demais seres singulares, são conatus, com a peculiaridade de que somente os humanos são conscientes de ser uma potência ou um esforço de perseveração na existência. O conatus, demonstra Espinosa na Parte III da Ética, é a essência atual do corpo e da mente. Mais do que isto. Sendo uma força interna para existir e conservar-se na existência, o conatus é uma força interna positiva ou afirmativa, intrinsecamente indestrutível, pois nenhum ser busca a autodestruição. $\mathrm{O}$ conatus possui, assim, uma duração ilimitada até que causas exteriores mais fortes e mais poderosas o destruam. Definindo corpo e mente pelo conatus, Espinosa os concebe essencialmente como vida, de maneira que, na definição da essência humana, não entra a morte. Esta é o que vem do exterior, jamais do interior (CHAUÍ, 2011, p. 84-5).

Por "perseverar na própria existência” podemos entender “[...] a expansão do corpo e da mente na busca da liberdade, da felicidade, que são necessidades tão fundamentais à existência 
DOI 10.33872/revcontrad.v2nl.e016 | v. 2, n. 1 | Jan./Jun. 2021

humana como o são os alimentos e os abrigos, e a reprodução biológica". Lutar pela emancipação humana é conservar-se na própria existência, saindo da heteronomia à autonomia (SAWAIA, 2009, p. 366). Sawaia (2009) ressalta as contribuições de Espinosa na superação da ideia de que a liberdade não é importante quando se está circunscrito ao "reino das necessidades". Além disso, a autora alerta que, embora Espinosa fale de essência, ele não é um essencialista, uma vez que a "potência de conservação é também poder de ser afetado [...]", em bons e maus encontros a que todos os seres humanos estão sujeitos na relação com o outro (SAWAIA, 2009, p. 366).

Espinosa apresenta três afetos primários, dos quais originam-se todos os outros:

[..] a alegria, ou o sentimento que temos do aumento de nossa força para existir e agir, ou da forte realização de nosso ser; a tristeza, ou o sentimento que temos da diminuição de nossa força para existir e agir, ou da fraca realização de nosso ser; e o desejo, ou o sentimento que nos determina a existir e agir de maneira determinada (CHAUÍ, 2011, p. 87, grifo do autor).

Assim, um afeto é considerado bom quando nos afeta de alegria. "Bom é tudo que aumenta a força de nosso conatus; mau, tudo que a diminui” (CHAUÍ, 2011, p. 90). Quando nossa capacidade de existir aumenta, somos ativos, e quando diminui, somos passivos. "Paixão equivale às ideias ilusórias e à passividade (ser determinado a existir, desejar e pensar com base em imagens exteriores que operam como causas de nosso apetite)" (SAWAIA, 2009, p. 367) ou como diria Chauí (2011), "a servidão é deixar-se habitar pela exterioridade [...]" (p. 91). A passagem da paixão (passividade) à ação (agir) é um caminho ético, o que não significa a mente dominar o corpo e nem eliminar os afetos. O percurso que transforma os afetos que são paixões em ações não é feito contra os afetos, mas graças a eles, se o conhecimento verdadeiro for um afeto. Isto porque uma "paixão não é vencida por uma ideia verdadeira, mas por uma outra paixão contrária e mais forte” (CHAUÍ, 2011, p. 97):

Espinosa nos mostra que a alegria e o desejo nascido da alegria (e, portanto, o desejo nascido de todos os afetos de alegria, como o amor, a amizade, a generosidade, o contentamento, a força de ânimo, a benevolência, a gratidão, a glória) são as paixões mais fortes. A vida ética começa, assim, no interior das paixões, pelo fortalecimento das mais fortes e enfraquecimento das mais fracas, isto é, de todas as formas da tristeza e dos desejos nascidos da tristeza (ódio, medo, ambição, orgulho, humildade, modéstia, ciúme, avareza, vingança, remorso, arrependimento, inveja). Uma tristeza intensa é uma paixão fraca; uma alegria intensa, uma paixão forte, pois fraco e forte se referem à qualidade do conatus ou da potência de ser e agir, enquanto a intensidade se refere ao grau dessa potência. Passar dos desejos tristes aos alegres é passar da fraqueza à força (CHAUÍ, 2011, p. 97-8). 
"A possibilidade da ação reflexiva da mente encontra-se, portanto, na estrutura da própria afetividade: é o desejo da alegria que a impulsiona rumo ao conhecimento e à ação" (CHAUÍ, 2011, p. 99). Assim, a reflexão como interiorização e discernimento das causas reais de nossas paixões é o que nos movimenta rumo à liberdade. "Em contrapartida, na ação e na liberdade, os humanos se descobrem como concordantes e, sobretudo, descobrem que sua força para existir e agir aumenta quando existem e agem em comum [...]" (CHAUÍ, 2011, p. 100). Bons encontros, portanto, pressupõem o outro, que é condição sine qua non da existência individual. Promover bons encontros, que aumentam a capacidade de cada humano em perseverar no seu ser, é promover liberdade e ação. Levando isso em consideração, apresentamos, em seguida, os depoimentos dos participantes da pesquisa a respeito de como sentiram a experiência de estar no círculo:

Mateus Foi legal porque eu aprendi coisa que eu não tinha aprendido antes, honestidade. (Adolescente, Ponta Grossa)

Natalia: Foi bom, foi uma experiência bem diferente assim, é uma experiência que a gente que nunca foi assim de sentar em família e conversar né [...]. (Mãe de adolescente, Ponta Grossa)

Rodrigo: Eu confesso para você que nas primeiras vezes eu fui daquele jeito que eu era antes assim, assim cara fechada, não queria falar com ninguém, mas depois, no último assim, que eu vi que era para valer mesmo, que ía... que era um negócio sério, aí a gente interagiu, a gente conversou, deu risada tudo, eu acho que foi bom, e tipo, de lá para cá tô dez vezes melhor do que eu era antes, porque... era crítico o negócio. (Adolescente, Ponta Grossa)

Priscila: Bom, eu nunca tinha participado de nenhum círculo, assim, restaurativo, pra mim foi uma experiência muito boa, eu aproximei mais minha família e meu filho, e ele pôde falar coisas que ele sente. (Mãe de adolescente, Caxias do Sul)

Elisa: [...] Mas nesse caso específico é uma coisa, assim, que eu vou levar para minha vida inteira, foi uma coisa muito fora do comum, e que... que deu certo sabe, então eu fico assim muito feliz porque eu já vi tantos casos que a gente poderia ter agido de uma forma diferente dentro da escola, eu sempre tive essa postura né de acreditar até o fim, até o fim mesmo. (Diretora da escola, Ponta Grossa)

Clara: Ah, eu sempre gosto e a gente também acaba se aliviando de muita coisa, porque a gente, no dia a dia, acumula tarefa e vai fazendo, vai fazendo e você não pára, de repente ali até você pára para analisar algumas coisas, porque você fala de você também né, você não tá lá pra falar do outro, todo mundo fala de suas vidas, o que, que marcou, então é muito interessante. (Assistente Social, Ponta Grossa)

Carolina: Como é que eu vou te explicar, bom o modo mais fácil de eu te explicar: solta o passarinho de uma gaiola. Eu me sinto, eu sou o passarinho, liberto [...] (Mãe de adolescente, Ponta Grossa) 
Nestes depoimentos podemos observar a liberdade subjetiva que decorre do entendimento, da reflexão sobre si, da inspiração na história do outro, da mudança de perspectiva sobre o encontro com o outro, da humanização do outro, da criação de um novo caminho à realização dos sonhos ou aos relacionamentos (a criatividade), que se expressa por afetos de alegria, diante de bons encontros. Quando nos deparamos com maus encontros, entretanto, as paixões tristes, representadas pela raiva, ódio, medo, vingança, remorso, entre outras, são reforçadas e esta também pode ser uma possibilidade que resulta dos encontros da justiça restaurativa, como podemos observar nos depoimentos seguintes:

Tomas: Pra mim, negativo que o professor levou muito pro lado pessoal, o coordenador, aí tipo assim, eu tô num grupo de amigos, aí ele finge que não me conhece, fala com meus amigos e não fala comigo e vai se embora. [...] Porque ele me tratava bem, conversava comigo, aí depois aconteceu isso, ele nem fala mais. (Adolescente, Icoaraci)

Tomas: A mudança né, porque eles até tratam os alunos melhor agora porque antigamente não era assim, [...] agora não, tem até casos que ela xingou alunos lá, porque não tinha comportamento, chamou de vagabundo aí agora não, ela tá tranqüila lá, tá mais comportada. Já o Frederico não, levou mais pro lado pessoal, a gente dá bom dia, ele não responde. (Adolescente, Icoaraci)

Apesar de não termos maiores informações documentais que possam corroborar nosso argumento a respeito da justificativa para este mau encontro, algumas hipóteses podem ser ventiladas, com base nos depoimentos do adolescente e seu pai, que contextualizam o caso em questão. Neste, especificamente, o aluno estava sendo acusado de levar drogas e bebidas para dentro da escola e embriagar outros adolescentes. Inicialmente, a escola havia decidido pela suspensão do aluno, quando, então, o pai do adolescente procurou o Ministério Público e foi lhe ofertada a realização de procedimento circular restaurativo como possibilidade de resolução da questão. A escola estava decidida pela resolução interna da questão, sem que fosse considerada a participação do outro lado, envolvido na história. Ter levado o conflito a uma instituição da justiça pode ter representado à escola uma espécie de punição, mesmo que esta não seja a finalidade da justiça restaurativa, porém descentrou a escola de uma decisão unilateral para o problema. Embora seja impossível ter controle sobre tudo o que venha a ocorrer no encontro restaurativo, há que se ter muito cuidado e vigilância quanto à promoção da horizontalidade no círculo, a fim de minimizar maus encontros.

Sobre os maus encontros, Espinosa os relaciona à servidão, cujos efeitos, no que se refere à vida intersubjetiva, contribuem para que os homens se vejam contrários uns aos outros, 
“[...] em luta contra todos os outros, temendo e odiando todos os outros, cada qual imaginando satisfazer seu desejo com a destruição do outro, percebido como obstáculo aos apetites e desejos de cada um e de todos os outros" (CHAUÍ, 2011, p. 91). De modo geral, observamos que este é o modo de relacionamento que predomina na sociedade e que a justiça restaurativa, como construtora de novas sociabilidades, tenta modificar. Concordamos que o processo de emancipação humana não se dá individualmente, mas sempre em relação com os demais homens. Aliás, é sempre para o Outro e em razão do Outro que os homens manifestam-se no mundo, desde o princípio (MARX, 1859). Apesar da obviedade desta afirmação, Marx não pôde deixar de observar que a concepção predominante que se tem a respeito do homem gira em torno da sua independência dos demais, como se suas ações fossem motivadas individualmente e cujo resultado, bom ou ruim, pertencesse, unicamente, ao autor da ação. Tal processo é ilusório e tem sido tarefa da Psicologia Social, de matriz sociológica, "buscar compreender por que o homem, que é um ser de relações, que sabe que sem o outro não há humanidade, transforma a alteridade em luta contra o outro e mesmo assim vive a ilusão da independência" (SAWAIA, 2006).

A situação acima mencionada nos leva à discussão da dimensão ética dos relacionamentos humanos. Segundo Sawaia (2006), a ética está presente na busca constante de uma sociedade mais justa e fraterna e do estabelecimento de normas que sejam cada vez mais construtoras de seres humanos livres e solidários. A ética, portanto, busca a libertação pessoal e social das pessoas e das situações de injustiça (SAWAIA, 2006). Estando um passo adiante da moralidade, a ética não se pauta por leis universais ou se preocupa com o controle e normalização dos comportamentos individuais, a sua preocupação principal está na necessidade de reafirmar o caráter social do ser humano, e isso significa reconhecer que as existências individuais somente são mantidas por uma coletividade. A não liberdade de um só existe com a não liberdade de muitos. Da mesma forma, um indivíduo livre só pode sê-lo por meio da liberdade dos seus semelhantes. Perceber a inter-relação que existe entre os seres humanos é condição para a conquista da própria autonomia humana. Nessa lógica, agir para o bem comum é agir para si mesmo (SAWAIA, 2006).

Inspirado em Espinosa e na teoria dialético-materialista de Marx, Vygotsky construiu uma concepção inovadora de psiquismo, "como um sistema integrado de funções psicológicas, em que todas estão relacionadas entre si, ao corpo biológico, mediadas pela cultura e pelo contexto social, sem hierarquia e relação causal" (SAWAIA, 2009, p. 368). Vigotski (2001) reconheceu que a teoria das emoções era o tema menos elaborado da psicologia no início do século XX, em virtude da dificuldade de descrevê-la e classifica-la, a 
partir de um paradigma de ciência positivista. Para Vigotski, em concordância com Espinosa, a emoção tem papel fundamental na organização e funcionamento do sistema psíquico, não sendo inferior ao pensamento. "Um comportamento emocionalmente colorido adquire um caráter inteiramente diverso do comportamento insípido. As mesmas palavras, porém pronunciadas com sentimento, agem sobre nós de modo diferente daquelas pronunciadas sem vida" (VIGOTSKI, 2001, p. 135). Para o autor, a emoção desempenha um importante papel no psiquismo, sendo a base afetivo-volitiva de nossos pensamentos e comportamentos:

Toda emoção é um chamamento à ação ou uma renúncia a ela. Nenhum sentimento pode permanecer indiferente e infrutífero no comportamento. As emoções são esse organizador interno das nossas reações, que retesam, excitam, estimulam ou inibem essas ou aquelas reações. Desse modo, a emoção mantém seu papel de organizador interno do nosso comportamento (VIGOTSKI, 2001, p. 139).

Vigotski (2001) chama a atenção ao caráter pedagógico das emoções, o que sinaliza a coerência do procedimento restaurativo com o caráter pedagógico das medidas socioeducativas, além de outras intervenções que sigam por esse caminho. Vigotski construiu sua teoria psicológica com o foco na educação, buscando "construir um novo homem para uma nova sociedade" no período em que viveu, fortemente influenciado pela Revolução Russa. Para ele, "nenhuma forma de comportamento é tão forte quanto aquela ligada a uma emoção" (VIGOTSKI, 2001, p. 143). Por isso, é preciso se preocupar, no processo pedagógico, em deixar vestígios emocionais no aluno. "Nenhuma pregação moral educa tanto quanto uma dor viva, um sentimento vivo, e neste sentido o aparelho das emoções é uma espécie de instrumento especialmente adaptado e delicado através do qual é mais fácil influenciar o comportamento" (VIGOTSKI, 2001, p. 143). Parafraseando Vigotski， o trabalho na socioeducação deve consistir não só em fazer com que os adolescentes pensem e assimilem a lei e os danos que causaram, mas também que o sintam ${ }^{50}$. Aprender, portanto, é emocionar-se:

Jaqueline: A gente sempre tá refletindo, às vezes não necessariamente tá batendo na tecla, [...], mas por exemplo, esse adolescente que teve o círculo agora, eu acho que ele entendeu a dimensão do que ele tinha feito quando ele viu a mãe dele chorando desesperada na Delegacia, e a mãe dele falando, "olha, porque não sei o que, a gente não imaginava tu tá aqui", e uma das coisas que ele trouxe, que ver a mãe dele chorando foi mais impactante que o sermão do juiz, que colocar ele ali, então as vezes acho que é isso, às vezes eles vendo o impacto que eles causaram na vida de quem eles mais amam, às vezes começa por aí. (Assistente Social, Caxias do Sul) 
Enquanto Espinosa compreendia a imaginação, como uma "imagem aparente das afecções", Vigotski viu na imaginação a base da criação humana. "Toda emoção faz uso da imaginação, pois é ela que amplia a experiência, permitindo ao sujeito se apropriar da experiência de outros, associar acontecimentos [...], mudar o passado, antecipar o futuro e, assim, promover transformações" (SAWAIA, 2006 apud SAWAIA, 2009, p. 369). Inspirada em Espinosa e Vigotski, Sawaia (2009) defende que a emoção e a criatividade são imprescindíveis à superação da desigualdade social, em virtude das suas dimensões ético-políticas. Para a autora, a principal contribuição de Vigotski à filosofia de Espinosa está no "papel da imaginação na liberdade humana, mediada pelas emoções, com base no vínculo da imaginação e do pensamento com a afetividade" (VIGOSTKI, 1993 apud SAWAIA, 2009, p. 369). Com base nesse entendimento, podemos acompanhar o depoimento de uma participante da pesquisa sobre as transformações que realizou após a participação nos círculos, que passou a exercer maior controle sobre sua vida, reconhecendo a emoção como base afetivo-volitiva do pensamento e do comportamento humano:

Carolina: Uma mudança que a gente morava todos em uma casa só, eu era divorciada, o pai dele não queria sair de casa por hipótese nenhuma e a gente, lá eu fui [...], eu fui conversando com outras pessoas, foi e descobri que era possível desmembrar minha casa, até portanto você pode ver minha casa está desmembrada, aí eu consegui ter minha vida só com os meus filhos e o pai deles ficou... pra muitos é uma parede que divide, um muro, pra mim não é, é a minha vida com os meus filhos e aí a gente tá agora, faz... faz um mês ou dois que a gente tá assim e é uma vida que eu tô começando com os meus filhos, só nós com a nossa vida. Então mudou, mudou, é outra vida. (Mãe de adolescente, Ponta Grossa)

Carolina: Porque melhorou muito minha vida sabe, dali porque eu tava num mundo assim que... sabe quando você tá num túnel, não vou dizer num túnel, quando você ta num... você tá num mundo onde você não vê saída, num círculo aonde você não vê saída, você olha por todos os lados e você não vê porta pra você sair. E quando eu cheguei lá, até essa situação que aconteceu com meu filho que levou a gente pra lá, foi assim como a saída. Pra mim foi uma saída, que eu vi que era possível eu alcançar um objetivo que eu queria e não via a saída. Eu saí da situação da qual eu vivia. Lá eu vi que é possível. (Mãe de adolescente, Ponta Grossa)

No depoimento desta participante podemos observar que a afetividade que permeou o encontro do círculo da justiça restaurativa significou uma mediação entre a passividade e a atividade na história desta participante. Estar separada, porém ainda em uma convivência que cerceava sua liberdade representava uma "mortificação" de sua própria subjetividade que, juntamente com o desamparo financeiro de seu ex-companheiro e intervenções inexistentes de apoio familiar como política pública construíram um cenário de vulnerabilidade social à 
família, visibilizada ao Estado pelo ato infracional cometido pelo seu filho adolescente. Paixões tristes, sentidas individualmente como incapacidade, desmotivação, inutilidade puderam ser transformadas por paixões alegres, que impulsionaram uma solução criativa para este aspecto de sua vida e que contribuiu, ainda, para fortalecer a função protetiva da família. "A alegria e a criatividade potencializam a força do nosso corpo e da nossa mente para não capitularmos ante as tragédias que a desigualdade social nos reserva [...]" (SAWAIA, 2009, p. 370).

Para Vigotski, o sujeito é constituído de determinações sociais, porém não é determinado. É, na verdade, "potencialidade de desenvolvimento mediado pelas intersubjetividades e atividades" (SAWAIA, 2009, p. 369), em virtude do significado, unidade analítica que atua na interligação das funções psicológicas com o corpo e a sociedade.

O movimento caracteriza a qualidade humanizada do ser humano. E esse movimento é constituído pela intersubjetividade. $\mathrm{O}$ outro também representa uma mediação de mim com mim mesma, numa relação dialética entre exteriorização e interiorização, objetividade e subjetividade. Este movimento, que é constante, nos permite ressignificar as relações que estabelecemos com o outro, com as instituições e com os nossos próprios projetos de vida. Podemos observar estes movimentos e a atenção ao objetivo de integrar socialmente o adolescente (SINASE) pelos depoimentos que seguem e que apresentam ressignificações relacionais (com profissionais e instituições):

Tomas: É que melhorou muito as coisas na escola, eles tomaram uma atitude de não ter mais aquele tom de voz com os alunos, tratar o aluno melhor, à base da conversa, não do grito. (Adolescente, Icoaraci)

Rodrigo: Ah, porque aquele negócio, eu não sou muito chegado que as pessoas me ajudem. Eu gosto mais de eu mesmo correr atrás, mas aqui ela já ajudou bastante, lá em casa, ela procura ajudar sabe, e antes eu não enxergava isso. Ela só era mais uma pessoa, e hoje eu sei que, tipo, ela é uma pessoa que se eu estiver dentro da instituição que se alguma coisa acontecer, que eu posso chegar aqui conversar com ela, trocar uma ideia com ela, é isso aí. (Adolescente, Ponta Grossa)

Elisa: Atitudes de... de... olhar para ele como uma criança normal, porque ele não era olhado, não por nós, mas de uma maneira geral, por ele se comportar dessa forma né, mais agitado, mais agressivo, as pessoas não conseguiam olhar pra ele como uma criança normal e a partir de tudo isso, das pessoas, porque não foi só ele que entendeu uma situação, de toda a comunidade que passou a entender ele de uma forma diferente né, ele era só o agressor... (Diretora de escola, Ponta Grossa)

Jaqueline: Eu creio que ele conseguiu me enxergar como uma pessoa que tá ali realmente pra ajudar [...]. (Assistente Social, Caxias do Sul) 
Clara: Muda, muda, é.... porque parece que eles te olham diferente né, "ela sabe da minha vida, ela entendeu o meu lado né, ela me ouviu", então isso pelo simples fato de você atender, olhar, escutar essa criança, eu acho que já muda muita coisa, porque esse é um grande erro, as pessoas só julgam, julgam, julgam, não deixam eles falarem então acho que isso acaba complicando mais ainda né. (Assistente Social, Ponta Grossa)

Os demais depoimentos apresentam o processo de ressignificação pessoal dos participantes, a partir da participação na justiça restaurativa:

Rodrigo: É, o combinado foi eu estudar, foi eu não largar de estudar, é progresso, procurar melhorar minhas atitudes e coisarada assim e foi o que eu fiz, eu tô estudando, tô mudando cada dia minhas atitudes, procurando mudar né, porque não existe ninguém perfeito, e é isso que eu tô fazendo. (Adolescente, Ponta Grossa)

Natalia: Eu acho que mudou porque eu era uma pessoa assim mais quieta, mais reservada, mais na minha, sabe, eu não era de chegar assim e dar um abraço no filho sabe, de dizer eu te amo, depois que a gente participou dessas coisas eu achei que eu mudei. (Mãe de adolescente, Ponta Grossa)

Mateus: Tipo, eu quando era para ir na diretoria antes eu não queria ir, agora eu vou, tipo eu vou para ver o que que é. (Adolescente, Ponta Grossa)

Mateus: Por causa que, tipo, quando eu briguei com ele assim, eu me senti culpado de tudo que eu tinha feito com ele, daí eu mudei depois que eu fui no círculo. (Adolescente, Ponta Grossa)

Questionamos este último adolescente quanto ao que ele faria se encontrasse o outro adolescente, por acaso. Nesse momento ele relatou já ter encontrado o adolescente na rua e completou dizendo como foi:

Mateus: Normal, passei como se nada tivesse acontecido com ele e ele também. (Adolescente, Ponta Grossa)

Aguinsky, Grossi e Santos (2012) afirmam que a participação da comunidade/rede intersetorial na justiça juvenil restaurativa permite ao adolescente ofensor identificar outras possibilidades para contribuir com sua comunidade, de forma positiva, ao mesmo tempo em que desenvolve "[...] um novo conceito de si, e a comunidade também pode enxerga-lo de outra maneira" (p. 71). Isso porque contar histórias apresenta o potencial de promover humanização, de permitir conhecer o outro para além do que ele aparenta e é onde, também, os envolvidos podem reconhecer pontos comuns nas histórias vividas situando-os em algum nível de igualdade, mesmo que a relação entre profissional e usuário seja assimétrica. 
Nos depoimentos apresentados acerca das ressignificações relacionais, percebemos que a relação entre profissionais e adolescentes/famílias, a partir do círculo, não é emocionalmente neutra, o que permite maior proximidade, confiança e respeito no relacionamento, ou seja, vínculo afetivo. Lembrando que, para Vigotski (2001), as "reações emocionais exercem a influência mais substancial sobre todas as formas do nosso comportamento e os momentos do processo educativo [...]" (p.143). A capacidade de desenvolver empatia pelos adolescentes e familiares é condição importante para a reunião dos envolvidos em um objetivo comum, em que todos contribuem para construir um plano de ações, o que colabora para gerar conexões que podem ampliar o acesso a bens sociais.

Considerando os parâmetros norteadores da ação pedagógica na execução das MSE, dispostos pelo Conanda (2006), Rodrigues e Oliveira (2016) reconhecem o quanto a socioeducação inclui a subjetividade no processo pedagógico: "Podemos considerar que a ação socioeducativa envolve, necessariamente, o estabelecimento de mecanismos dialógicos de ressignificação acerca da prática infracional, dos projetos de vida e das visões de mundo desses adolescentes" (RODRIGUES; OLIVEIRA, 2016, p. 113).

Lembramos que a vulnerabilidade está associada à oferta de oportunidades, por um lado - "termo que identifica o conjunto de recursos, bens e serviços, programas, benefícios colocados à disposição de públicos com diferentes níveis e tipos de vulnerabilidade" (BRONZO, 2007, p. 03) - e por outro lado, está associada à capacidade das famílias em acessar as oportunidades, que é a dimensão psicossocial:

De um lado, fatores exógenos às pessoas e famílias e de outro fatores endógenos a elas. Disso decorre que, para enfrentar de forma efetiva e sustentável as condições de vulnerabilidade, qualquer estratégia tem, necessariamente, que passar pela alteração positiva da estrutura de oportunidade e pelo fortalecimento dos ativos, pela busca de autonomia e protagonismo dos indivíduos e famílias (BRONZO, 2007, p. 03).

Com isto, podemos concluir que o acesso/aquisição de bens sociais (educação, trabalho, saúde, habitação, justiça e outros) às famílias dos adolescentes autores de ato infracional, que lhes propiciem desenvolver suas capacidades e entrar em contato com a produção cultural, material e intelectual do desenvolvimento histórico da humanidade demanda não só a oferta de oportunidades e serviços, mas a disposição das famílias em acessá-los, efetivamente. “A desinformação, o isolamento e as características psicossociais [...]” presentes nas situações de vulnerabilidade social dificultam o acesso a bens, serviços e programas pelas famílias (BRONZO, 2007, p. 07). Isso requer, sobretudo, o fortalecimento do “[...] repertório de 
respostas, expandir capacidades e fronteiras de pensamento e ação" (BRONZO, 2007, p. 04). Levando isso em consideração, Bronzo (2007) aponta que a superação da vulnerabilidade e da pobreza passa pelas famílias, sua dimensão não só concreta, como subjetiva, relacionada a valores, comportamento e autonomia.

\begin{abstract}
Alterar o cenário de pobreza requer, além de uma estrutura de oportunidades adequada, atenção à qualidade dos laços sociais, às condutas e ações que grupos, indivíduos, famílias e comunidades realizam para lidar com sua situação de pobreza e vulnerabilidade (BRONZO, 2007, p. 04, grifo nosso).
\end{abstract}

É por esta razão que consideramos a participação da rede intersetorial na justiça juvenil restaurativa como necessária ao processo de aquisição de bens sociais, uma vez que compreendemos o ato infracional como expressão da vulnerabilidade, que é uma demanda para a rede. Por outro lado, considerando a especificidade relacional e afetiva da metodologia dos círculos de construção de paz, compreendemos como uma oportunidade de construir vínculos entre adolescentes, famílias e profissionais dos serviços que podem, desse modo, convergir para um objetivo comum de enfrentamento da vulnerabilidade social.

\title{
4 Considerações finais
}

Este Relato de Pesquisa teve por objetivo compreender a potencialidade dos encontros com a rede no atendimento ao adolescente autor de ato infracional e sua família a partir de um contexto de vulnerabilidade social. Nos depoimentos apresentados nesta pesquisa, observarmos a presença de importantes contribuições do encontro a partir da metodologia da justiça restaurativa para o enfrentamento às condições de vulnerabilidade social e acesso a direitos, que foram: o encontro intersetorial no círculo, a empatia dos profissionais, a motivação e ressignificação dos adolescentes, o afeto e atenção à "qualidade dos laços sociais", vínculos construídos entre profissionais e família.

É possível concluir que os profissionais da rede que participam nos procedimentos da justiça juvenil restaurativa podem atuar como "apoios familiares" ${ }^{1}$, que são entendidos por Bronzo (2007, p. 09) como:

[...] os agentes catalisadores do processo, gerando vínculos para o desenvolvimento das famílias, atuando como conectores das famílias às redes diversas, fortalecendo o desenvolvimento de processos familiares que, juntamente com a garantia de satisfação de necessidades básicas, permitem às famílias fortalecer sua capacidade de resposta, reduzindo sua vulnerabilidade. 
Percebemos com isso, que a autonomia, o protagonismo das famílias, a ampliação da capacidade de escolha e de controle sobre sua vida é um produto que emerge das relações que se estabelecem entre profissionais e famílias, quando regidos por uma lógica intersetorial, pela horizontalidade das relações entre familiares e profissionais, pelo vínculo e afeto mobilizados. Entretanto, a mesma autora lembra que a confiança que se estabelece entre profissionais e família é bastante sensível e está vinculada, de certa forma, à "capacidade de resposta e atuação do poder público junto às comunidades e famílias" (BRONZO, 2007, p. 05), ou seja, é preciso que as oportunidades e os bens sociais estejam disponíveis às famílias. Além disso, a frequência de encontros nesses casos parece ser maior, uma vez que as necessidades das famílias são amplas e se modificam rapidamente, o que requer acompanhamento e estabelecimento de novas metas, sendo esta uma preocupação importante na operacionalização da justiça juvenil restaurativa no contexto brasileiro.

\section{Referências}

AGUINSKY, B. G.; GROSSI, P. K.; SANTOS, A. M. A questão da comunidade na interface com a Justiça Restaurativa: algumas polêmicas e a perspectiva do capital social. In: PETRUCCI, Ana Cristina Cusin [et. al] (Org.). Justiça juvenil restaurativa na comunidade: uma experiência possível. Porto Alegre: Procuradoria-Geral de Justiça, Assessoria de Imagem Institucional, 2012.

BRASIL. Lei $\mathrm{n}^{\circ}$ 12.594. Institui o Sistema Nacional de Atendimento Socioeducativo (Sinase). Diário Oficial da União, Brasília, 18 de Janeiro de 2012. Disponível em: http://www.planalto.gov.br/ccivil_03/_ato2011-2014/2012/lei/112594.htm Acesso em 05 mai. 2016.

CHAUÍ, M. Desejo, paixão e ação na ética de Espinosa. São Paulo: Companhia das Letras, 2011.

MARX, K. Introdução à contribuição para a crítica da economia política. 1859. Disponível em: http://www.marxists.org/portugues/marx/1859/contcriteconpoli/introducao.htm Acesso em: 13 out. 2016.

NETTO, J. P. Introdução ao método na teoria social. In: CFESS/ABEPSS. Serviço Social: direitos sociais e competências profissionais. Brasília-DF, 2009.

PRANIS, K. Processos Circulares. São Paulo: Palas Athena, 2010.

RODRIGUES, D. S.; OLIVEIRA, Maria Cláudia Santos Lopes de. Psicologia cultural e socioeducação: reflexões sobre desenvolvimento humano e infração juvenil. Rev. Subj., Fortaleza, v. 16, n. 1, p. 104-118, abr. $2016 \quad$. Disponível em http://pepsic.bvsalud.org/scielo.php?script=sci_arttext\&pid=S2359-

07692016000100009\&lng=pt\&nrm=iso Acessos em:

out. 2018. http://dx.doi.org/10.5020/23590777.16.1.104-118. 
SAWAIA, B. O sofrimento ético-político como categoria de análise da dialética exclusão/inclusão. In: SAWAIA, B. B. (Org). As artimanhas da exclusão: análise psicossocial e ética da desigualdade social. $11^{\circ}$ ed. Petrópolis, RJ: Vozes, 2011.

SAWAIA, B. Psicologia social: aspectos epistemológicos e éticos. In: LANE, S. T. M.; SAWAIA, B. (Orgs). Novas veredas da psicologia social. São Paulo: Brasiliense; Educ, 2006.

SAWAIA, B. Psicologia e desigualdade social: uma reflexão sobre liberdade e tranformação social. Psicol. Soc., Florianópolis, v. 21, n. 3, p. 364-372, Dec. 2009 . Available from http://www.scielo.br/scielo.php?script=sci_arttext\&pid=S010271822009000300010\&lng=en\&nrm=iso Accesso em: $27 \quad$ Jan. 2019. http://dx.doi.org/10.1590/S0102-71822009000300010.

SILVA, E. R. A. da; OLIVEIRA, R. M. de. O Adolescente em conflito com a lei e o debate sobre a redução da maioridade penal: esclarecimentos necessários. IPEA: Nota Técnica, Brasília, 2015.

Disponível em: http://www.ipea.gov.br/portal/images/stories/PDFs/nota_tecnica/150616_nt_maioridade _penal.pdf Acesso em $15 \mathrm{Jul} / 2017$.

SPINOZA, B. Ética. [Tradução de Tomaz Tadeu]. Belo Horizonte: Autêntica, 2009.

VIGOTSKI, L. S. Psicologia pedagógica. [Tradução Paulo Bezerra]. São Paulo: Martins Fontes, 2001.

\footnotetext{
${ }^{i}$ Graduada em Psicologia pela Universidade Estadual do Centro-Oeste, mestre e doutora em Ciências Sociais Aplicadas pela Universidade Estadual de Ponta Grossa. Servidora municipal, atua no Centro Judiciário de Solução de Conflitos e Cidadania. Professora no curso de Psicologia e curso de Direito da UNICESUMAR. Email: glauciamno88@gmail.com

ii Graduada em Direito pela Universidade Estadual de Ponta Grossa, mestre e doutora em Direito das Relações Sociais pela Pontifícia Universidade Católica de São Paulo. Atualmente é professora adjunta da Universidade Estadual de Ponta Grossa no programa (mestrado e doutorado) em Ciências Sociais Aplicadas e na graduação e pós-graduação no Curso de Direito. Email: dirceiam@gmail.com

iii Graduada em Serviço Social pela Universidade Estadual de Ponta Grossa, mestre em Prática Profissional e Política Social pela Pontifícia Universidade Católica de São Paulo e doutora em Serviço Social pela Pontifícia Universidade Católica de São Paulo. Atualmente é professora associada da Universidade Estadual de Ponta Grossa junto ao Curso de Serviço Social e ao Programa de Pós-Graduação em Ciências Sociais Aplicadas. Email: juaybo@gmail.com
} 